\title{
Study on the Ecological Environmental Protection System of Songjiang District
}

\author{
Guo-Dong YAN ${ }^{1, a}$, Ya-Nan CAI ${ }^{1, b}$, Guo-Wei YAN ${ }^{2, *}$, and Shuang-Shuang LIU ${ }^{1, c}$ \\ ${ }^{1}$ School of management, Shanghai University of Engineering Science, Shanghai International Cruise Business Institute NO,333 Longteng \\ Road, Shanghai, China. \\ ${ }^{2}$ shanghai Lixin University of accounting and finance,NO 2800 Wenxiang Road, Shanghai, China \\ ${ }^{a}$ Yanguodong@163.com, ${ }^{b} 3295229749 @ q q . c o m,{ }^{c}$ nanluk@qq.com \\ *Corresponding author: 15618592002@163.com
}

\begin{abstract}
For Strong and Optimize Shanghai Ecological Environmental System. Shanghai has increased its investment in ecological environmental protection. Songjiang ranks the first in terms of environmental quality in all districts for 8 consecutive years. All the above achievements are due to the efficient and fast optimization and upgrading in its ecological environmental system. This paper focuses on analyzing the features of the ecological environmental protection system of Songjiang, clarifying clarifies the main bottlenecks, and puts forward corresponding countermeasures and suggestions to provide references for relevant government departments.
\end{abstract}

\section{Introduction}

Strong and Optimized Shanghai Ecological Environmental System. Shanghai has increased its investment in ecological environmental protection. Spending on energy conservation and environmental protection projects has accounts for $70 \%$ of the overall budget of Shanghai Municipal Environmental Protection Bureau. In 2003, Shanghai Environmental Protection and Coordination Committee were set up with seven special working groups and 10 operation mechanisms were established. In 2008, the Special Fund for Energy Conservation and Emission Reduction was established in Shanghai. The document of Several Suggestions on Establishing the Sound Ecological Compensation Mechanism which was established in 2009 explicitly adopted the basic principles of "Government takes the main responsibilities while the market takes the auxiliary responsibilities." Through analyses, it is found that during the five rounds of the Shanghai environmental protection three-year plans, policy mechanism accounts for growing proportions of the total projects in recent years. The fifth round of policy mechanism projects accounted for $17.91 \%$ of the total projects. A number of subsidy policies were adopted by the Municipal finance on the basis of environmental protection infrastructure projects.

Remarkable Achievements were made by Songjiang District in Ecological Environmental Protection. Songjiang District successively won the honorary titles such as the "International Garden City", "National Sanitary District", "National Green City Model ",
"Chinese Inhabitable Environment Model", "Top Ten Leisure Cities of China", etc. Songjiang ranks the first in terms of environmental quality in all districts for 8 consecutive years. All the above achievements are due to the efficient and fast optimization and upgrading in its ecological environmental system. This paper focuses on analyzing the features of the ecological environmental protection system of Songjiang, clarifies the main bottlenecks, and puts forward corresponding countermeasures and suggestions to provide references for relevant government departments.

\section{Features of the Ecological Environmental Protection System of Songjiang District}

The Ecological Environmental Protection System is vigorously promoted. To effectively promote the regional environmental protection work, the Songjiang Environmental Protection and Coordination Committee was established in 2002, ensuring the smooth implementation of the Three-year Environmental Protection Plan. In 2013, Songjiang Afforestation and City Beautification Administration approved the establishment of the Federation of City Beautification, Environment Protection and Sanitation. In June 2013, the township simple garbage enclosures were all demolished, and RMB 5580 per Chinese mu were compensated according to the storage area. Songjiang implemented the "Green Account" step by step in four streets, and 6 street towns including Jiuting, Xinqiao, etc. 
Residents are encouraged and subsidized to sort dry and wet garbage, and scan the bag bar codes when discarding garbage. In 2014, Shanghai Afforestation and City Beautification Administration assigned the administrative rights of "Urban Life Garbage Commercial Cleaning Service" to districts and towns.

Sound Long-term Management Mechanism. Songjiang District has set up a sound long-term management mechanism. Established the work mechanism of information interaction and joint law enforcement and publicity, and effectively improved the administrative management efficiency. The Social Public Participation Mechanism was established and the "Environmental Protection Guardian" teams were established covering all 16 streets and towns in the district, such as the "Environmental Protection Volunteer" team, Citizen Patrol team, Community Red Armbands, Patriotic Sanitary Inspectors, etc. The "Microblog Netizen Patrol Team" was recruited publicly by Songjiang Afforestation and City Beautification Administration Bureau.

Integrated Joint Mechanism of Environmental Administrative Localization Administration In 2012, Suggestions on the Administrative Localization Implementation of the Songjiang District Afforestation \& City Beautification, and City Administration, and its supporting implementation proposals, evaluation methods and detailed rules were drafted and put into operation by all streets and towns on January 1st, 2014. Through administrative localization, unified rights and responsibilities, urban integration, and classified implementation, the government coordination functions are strengthened, the administrative function of government departments are transformed, the administrative localization efficiencies are deepened, the urban administration focus is continuously promoted towards a downward direction, and the new urban administrative framework is actively built featuring "clear responsibilities, joint interaction, comprehensive management, scientific efficiency".

Regulation Inspection and Reinforce Monitoring of Environmental Quality. The establishment of Songjiang Beautification, Environmental Protection, and Sanitation Comprehensive Evaluation System focuses on joint interactions between the district and subsidiary towns. "Daily Patrol, Night Inspection, Weekly Supervision, and Quarterly Evaluation" in terms of environmental protection and sanitation are carried out in 16 street towns (parks), full-day and all-round quality inspections are implemented to realize efficient supervision featuring "timely discovery, fast treatment, effective resolution, and forceful inspection". In 2013, based on the unified quality inspection platform of the city, Songjiang Environmental Protection authority carried out all-day, and all-round effective inspections on 1573 samples in the district. The Laboratory Information Management System (LIMS) was officially approved in 2013, and the third party evaluation was introduced into the environment and sanitation inspection. 7 sub-systems under Songjiang
Environmental Protection Bureau were integrated to form the Songjiang Pollutant Inspection Platform, which was officially accepted by Shanghai Environmental Protection Bureau on Dec 21st, 2012.

\section{Dilemma of Songjiang Ecological Environmental System}

Law Enforcement Supervision and Responsibility Mechanism are yet to be perfected. The current law enforcement supervision mechanism is imperfect. The environmental protection department and the other functional departments are peer government departments, therefore work coordination and supervisory management are unable to be effectively carried out. The comprehensive environmental law enforcement performances are inadequate. Besides the hot and difficult problems coordinated and resolved by city (district) government, the environmental protection authorities lack coordination capacity. Weaknesses existing in the law enforcement and inspection mechanism: there are difficulties existing in the coordination between the environmental protection authorities and other functional departments, especially in inspection implementation; there are no clearly identified methods on supervision in laws and regulations. Weaknesses existing in the law enforcement responsibility system: there are no concrete implementations on the Mayor and District Mayor Accountability System. Weaknesses existing in government employee performance assessment mechanism: the assessment is GDP oriented with low-level of citizen participation.

The Ecological Construction Mechanism is yet to be perfected. First, the financing of ecological compensation mainly relies on government transfer payments and special funds. Second, the department oriented ecological compensation lacks explicit responsibility body and clear work divisions, so that there are overlapped administrative responsibilities. Third is the over narrow scope and low standard of ecological compensation. Fourth, there is insufficient stability in the "Engineering Project" compensation mode.

\section{Discussion on Optimization of the Ecological Environment Protection System of Songjiang District}

Optimize the Property Right System of Resources and Environment. We should optimize the mechanism of ecological compensation. First is to accelerate the process of ecological compensation legislation, further clarify the funding sources, key areas, compensation methods, and compensation standards, and define the rights and obligations between relevant stakeholders and the guarantee measures; Second is to increase the fiscal transfer payments from the Central and Shanghai governments; Third is to speed up the reform on resource 
taxes, timely impose environment tax, and provide stable funding sources for ecological compensation; Fourth is to broaden the financing channels, and encourage social capitals to participate in the ecological environment construction and maintenance. We should improve the system of resource property rights. First is to optimize the resource property right system, and establish the system of resource paid usage; Second is to reconstruct the system of resource taxes and environmental taxes; Third is to speed up the reform on market structures of resource industry; Fourth is to optimize the means of price control, and establish the mechanism for the government to appropriately intervene price regulations of resource products. Fifth is to increase the prices of resource products, reduce the prices of renewable resources, and raise up the waste discharge costs.

Establish a Comprehensive Decision-making Mechanism on Environment and Development .We should improve the decision-making mechanism of multiple participation. We should build up the policy oriented department coordination mechanism, and implement the veto mechanism on policies and planning failed to pass the environmental impact assessment; We should suspend the approval of new construction projects with new pollutants in areas exceeding the total pollutant emission standards; We should suspend the approval of construction projects with relatively great ecological impact in severely polluted areas or areas without completing the task of ecological recovery. We should highlight the environmental impact assessment system. First is to carry out environment evaluations targeting high energy consuming and highly polluting industries, industrial parks, and hydropower bases; Second is to perfect the corresponding management mode connecting new project examination and approval with pollution emission reduction, according to the regional and industrial planning environment examination regulations; Third is to advance the separation between environmental protection composition institutions and examination and approval authorities, and set up independent legal environment protection agencies; Fourth is to clearly define the responsibilities of all parties, and increase penalties on legal violations. The public participation mechanism should be promoted. First is to enrich the ways of environmental publicity and education; Second is to define decision-making participation rights, environmental supervision and environmental litigation rights of non-governmental organizations and individual citizens; Third is to strengthen environmental information disclosure, according to the potential pollution degrees and levels to the environment caused by enterprises, and conduct classification management; Fourth is to formulate and perfect the NGO environmental laws and regulations as soon as possible.

Strengthen the Supervision and Management Retroactive Mechanism .The punishment mechanism on environmental damage activities should be established. First is to raise the charging standards according to the principle of "Making discharge standard higher than governance cost"; Second is to greatly increase the penalty on illegal behaviors; Third is to innovate the punishment methods on environmental damage behaviors, according to the uncapped "daily penalty"; Fourth is to improve the environmental pollution accident investigation system, the environmental pollution damage compensation system and the system of environmental public interest litigation. The environment related law enforcement capacity should be strengthened. First is to establish and perfect the environment law enforcement agencies, and form the provincial, county and township level environmental law enforcement supervision network; Second is to increase investments in the environmental law enforcement, and improve the level of law enforcement equipment; Third is to strengthen the construction and training of the environmental law enforcement teams; Fourth is to standardize the procedures of the environmental law enforcement system; Fifth is to strengthen cooperation between departments, and innovate the mechanism of law enforcement. Supervisions on ecological civilization construction should be strengthened. First is to strengthen the supervision of various levels of the National People's Congress on ecological civilization construction; second is to strengthen the judicial supervision, and actively promote the implementation of the "Environmental Impact Assessment System"; Third is to strengthen social supervision.

Deepen the Reform on the Resource and Environment Administrative System. The inter-departmental coordination mechanism should be built. We should set up Songjiang Leadership Group for Ecological Civilization Construction, organize Songjiang environmental protection joint meetings, and conduct resource and environment administrative system reform step by step. The establishment of primary level environmental protection agencies should be strengthened. We should flexibly adopt the local environment management systems and advocate vertical management in accordance with the principle of "matching rights with responsibilities and delegating rights to lower levels". We should set up local offices of township environment protection bureaus in key towns of Songjiang, receiving vertical administration from the district environment protection bureau, or set up special positions responsible for environment protection work in township governments. Joint prevention and control mechanism targeting air pollution should be promoted. We should carry out "smog" treatment accountability mechanism, set up corresponding air pollution control and prevention regulations. The environmental law enforcement authorities should eliminate the negative interference of local interests, according to the vertical management mode, expand the PM10 and PM2.5 particles disclosure channels, and establish and perfect the accountability system for excessive discharge of atmospheric pollutants. 


\section{Acknowledgement}

This research was financially supported by the Shanghai government decision-making consultation project of Research on the path of making cruise supporting industrial park relying on the Wusong International Cruise Port (2015/2016-Z-J03), We are grateful for their valuable comments.

\section{References}

1. Johan Jansson \& Agneta Marel. Green Consumer Behavior: Determinants of Curtailment and Eco-innovation Adoption. Journal of Consumer Marketing Vol. 27, 2010

2. Xiangrong Liu, in:Ecological Civilization Development Strategy Study,People's Publishing House, Beijing,2013.
3. Yuanchun Peng, in: Unban Residents' Environmental Behavior Study, Guangming Daily Press, Beijing,2013.

4. Dayong Hong, in: Empirical Research on Chinese Residents' Concern and Behavior Based on the Environment-friendly Society, China Renmin University Press,Beijing,2012.

5. Ecology Civilization Research Center of Beijing Forestry University, in:Chinese Provincial Eco-civilization Construction Evaluation Report,Social Sciences Academic Press, 2013.

6. Lang Zhang:The Change of Shanghai Ecological Resources Use Mode Promote Green Space System Mutation. Territory \& Natural Resources Study.(2013) 